\title{
Evaluation of swell behaviour of expansive clays from specific moisture capacity
}

\author{
Alejandro Pino ${ }^{1, a}$, Aravind Pedarla ${ }^{1}$, Anand Puppala ${ }^{1}$, and Laureano R Hoyos ${ }^{1}$ \\ ${ }^{1}$ The University of Texas at Arlington, Department of Civil Engineering, Arlington, Texas 76019 USA
}

\begin{abstract}
Current swell characterization techniques used to interpret the mechanical volume change occurring during the swelling process are not successful due to lack of inclusion of influential properties. Accurate prediction of swelling behaviour allows us to design more efficiently and with better reliability. This research aims at developing a more comprehensive framework to predict swell potential. Laboratory studies are conducted on five natural expansive soils with different degree of expansiveness. Initial studies include determination of basic soil characterization, swell strains and swell pressures at their compacted state along with their inherent mineralogy. Later, replicate samples were studied for soil water characteristic curves using standard pressure cell apparatus and filter paper techniques. The path traversed by the specimen during swelling process is representative of the soil water characteristic curve of the same specimen. Hence, studies are pursued to understand the relationship between degree of expansiveness and the specific moisture capacity relative to that particular range of suction head. Test results showed that the degree of expansion represented by swelling strain or swelling pressure is proportional to the specific moisture capacity determined during the swelling process.
\end{abstract}

\section{Introduction and background}

Inherent chemical nature of expansive soils leads to the complex swell/shrink behaviour thereby leading to premature failures in civil infrastructure. Robust design of structures on these soils requires accurate assessment of the swelling behaviour [1]. In the last few decades, the swelling potential of soils has been linked to parameters like void ratio, moisture content, liquid limit and activity through empirical methods. However, studies have been performed and proved the incompleteness of the soil behaviour characterization when correlations based on such parameters are applied [2].

Swelling behaviour of expansive clays is highly influenced by their moisture/suction state, mineralogy, pore distribution and in-situ stress state. Several semiempirical models based on matric suction have been proposed including volume change constitutive relationships or statistical correlations [3, 4]. Many researchers including Berniner et al [7] and Delage et al. [8] studied the relationship between matric suction and swelling behavior of expansive clays. Pedarla et al. [9] conducted suction studies on two expansive clays with different mineralogy and found that mineralogy plays an important role in the swell-shrink and suction characteristics of the clay.

In the current work, the identification of swelling behaviour of compacted clay specimens is relied on the initial matric suction, the air/water-entry suction and the slopes of logarithm of soil suction-void ratio relationship.
These factors are considered to play an important role in the volume change potential. The slope of the SWCC or specific moisture capacity has been used to determine the swell behaviour for natural compacted clays.

\section{Experimental study}

For this study, five natural expansive soils were collected from different parts of the United States and named after the locations from where they were sampled. Basic soil characterization on these test samples is conducted and the details of the results are presented in Table 1. Also, Standard Proctor tests were conducted to establish the compaction relationships of the soils.

Samples were compacted at maximum dry density (MDD) and $95 \%$ of maximum dry density using a constant strain compactor method prescribed in the AASHTO T-307 standard intending to minimize the soil layering effects induced by the impact compaction method. Samples compacted at 95\% MDD were prepared at the same optimum moisture content condition as at MDD. From Table 1 it can be observed that Colorado soil exhibited highest plasticity indices value whereas Plano soil exhibited least indices.

One dimensional swell strain and swell pressure tests were performed in a conventional consolidometer setup following Method C (loading-after-wetting test) normalized in the ASTM D4546 - 08 standard. Appliance correction factors were applied to each of the

\footnotetext{
a Corresponding author: alejandro.pinobravo@mavs.uta.edu
} 
swell pressure tests for the determination of corrected swell pressure [5].

Table 1. Laboratory tests results.

\begin{tabular}{cccccc}
\hline Soil & LL & PI & $\begin{array}{c}\text { MDD } \\
\left(\mathbf{k N} / \mathbf{m}^{3}\right)\end{array}$ & $\begin{array}{c}\text { OMC } \\
\mathbf{( \% )}\end{array}$ & $\begin{array}{c}\text { USCS } \\
\text { Classification }\end{array}$ \\
\hline Burleson & 55 & 37 & 1633 & 19 & $\mathrm{CH}$ \\
\hline Colorado & 63 & 42 & 1649 & 19 & $\mathrm{CH}$ \\
\hline Grapevine 2 & 46 & 26 & 1693 & 19 & $\mathrm{CL}$ \\
\hline Mansfield & 67 & 38 & 1489 & 26 & $\mathrm{CH}$ \\
\hline Plano & 24 & 12 & 1462 & 27 & $\mathrm{CL}$ \\
\hline
\end{tabular}

A typical swell strain plot is depicted in Figure 1. The plot shows the vertical swell strain readings versus elapsed time period of a compacted Burleson soil specimen at MDD and 95\% MDD. Also, a typical loadback swell pressure plot of the compacted Burleson soil specimen is shown in Figure 2. The sample is allowed to free swell from an initial void ratio ' $\mathrm{e}$ '. After the completion of swell process, the sample is loaded systematically to allow the sample to reach its initial void ratio 'e'. The figure depicts void ratio versus overburden pressure at 95\% MDD. As expected, the specimens of the soils compacted at 95\% MDD condition exhibited lower values of swell strains and pressures than those exhibited by the specimens compacted at MDD.

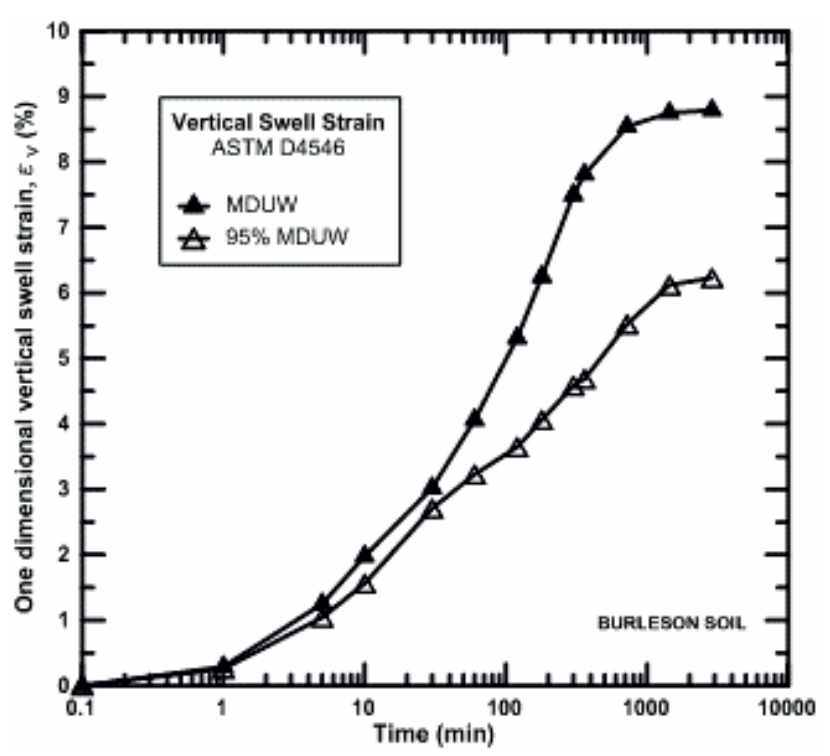

Figure 1. One dimensional swell strains for Burleson soil.

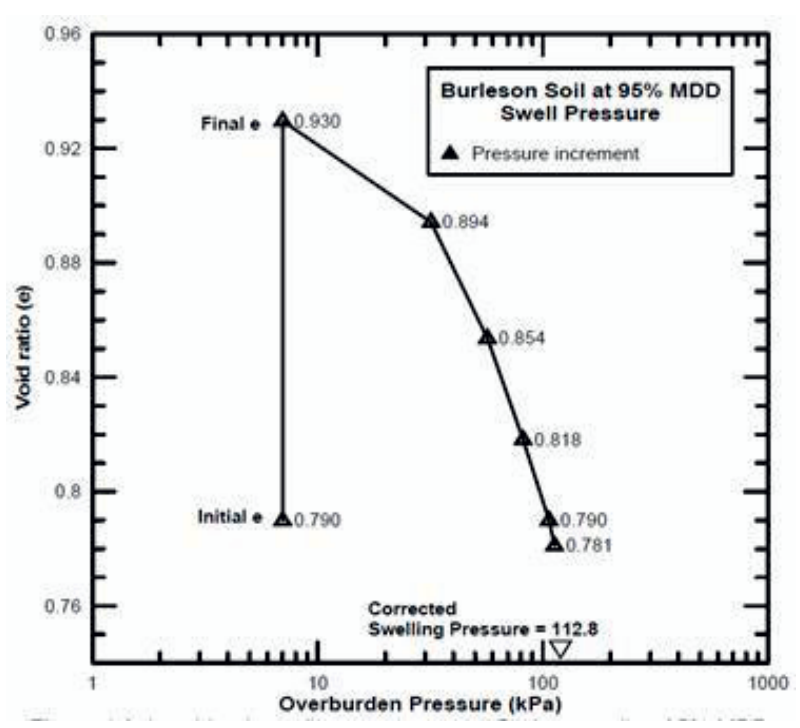

Figure 2. Load-back swell pressure test on Burleson soil at 95\% MDD.

Table 2 presents a summary of the results obtained from similar testing procedures conducted on the remaining 4 sampled soils along with their plasticity index property.

Table 2. Laboratory tests results.

\begin{tabular}{cccccc}
\hline Ranking & & $\begin{array}{c}\text { 1-D Swell strain } \\
(\%)\end{array}$ & \multicolumn{2}{c}{$\begin{array}{c}\text { Swell Pressure } \\
(\mathrm{kPa})\end{array}$} \\
\hline Soil & PI & MDD & $\begin{array}{r}95 \% \\
\text { MDD }\end{array}$ & MDD & $\begin{array}{r}95 \% \\
\text { MDD }\end{array}$ \\
\hline Colorado & 42 & 12.0 & 8.2 & 194.0 & 137.7 \\
\hline Mansfield & 38 & 11.7 & 9.5 & 164.2 & 138.9 \\
\hline Plano & 12 & 9.1 & 7.7 & 158.0 & 108.0 \\
\hline Burleson & 37 & 8.8 & 5.8 & 183.4 & 112.8 \\
\hline Grapevine 2 & 26 & 6.2 & 4.3 & 88.3 & 82.7 \\
\hline
\end{tabular}

Drying and wetting soil water characteristic curves (SWCCs) for the 5 test soils are determined using filter paper technique and dew point potentiometer method [6]. SWCCs are determined for samples compacted at $95 \%$ MDD condition. Therefore, the model proposed herein will be developed based solely on the tests results acquired for the $95 \%$ MDD condition.

SWCC for Burleson soil is presented in Figure 3. Similar studies were conducted for the rest of the test soils. Van Genuchten (1980) fitting model is utilized to fit the experimental data. Associated curve fitting parameters ' $a$ ', ' $n$ ' and ' $m$ ' for all the test soils are presented in Table 3. 


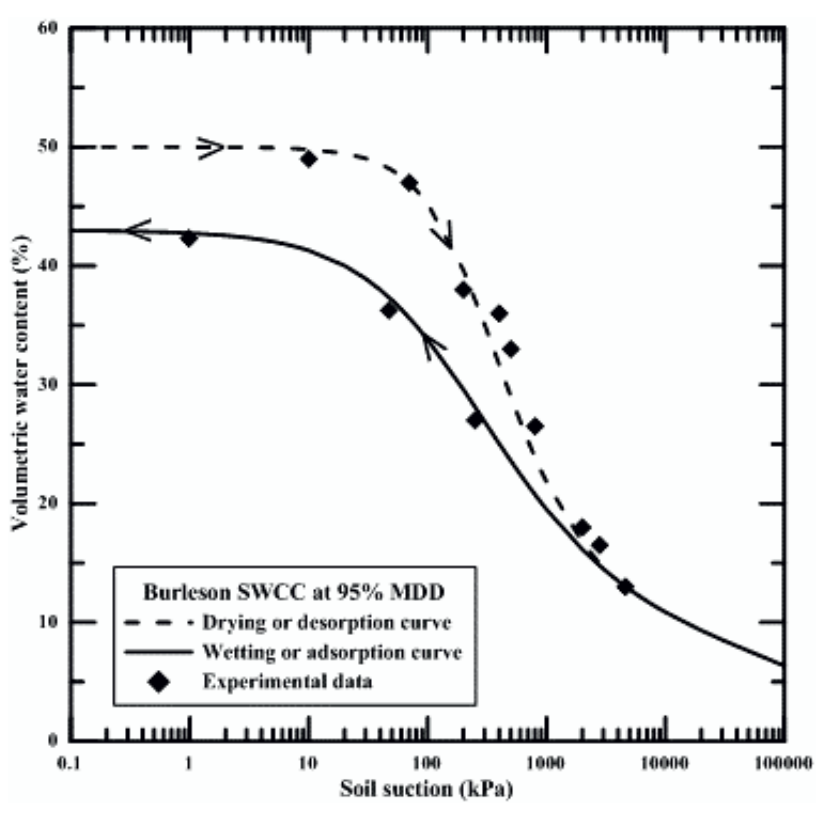

Figure 3. Soil water characteristic curves of Burleson soil at 95\% MDD.

Table 3. Curve fitting parameters for SWCCs based on Van Genuchten (1980) model.

\begin{tabular}{ccccccc}
\hline \multirow{2}{*}{ Soil } & \multicolumn{3}{c}{ Drying SWCC } & \multicolumn{3}{c}{ Wetting SWCC } \\
\cline { 2 - 7 } & $\mathrm{a}$ & $\mathrm{n}$ & $\mathrm{m}$ & $\mathrm{a}$ & $\mathrm{n}$ & $\mathrm{m}$ \\
\hline Burleson & 0.005 & 1.55 & 0.35 & 0.033 & 1.15 & 0.13 \\
\hline Colorado & 0.004 & 1.60 & 0.37 & 0.004 & 1.60 & 0.38 \\
\hline Grapevine 2 & 0.007 & 1.46 & 0.32 & 0.068 & 1.12 & 0.10 \\
\hline Mansfield & 0.002 & 1.58 & 0.367 & 0.027 & 1.11 & 0.10 \\
\hline Plano & 0.013 & 1.27 & 0.300 & 0.025 & 1.11 & 0.10 \\
\hline
\end{tabular}

\section{Modified specific moisture capacity $(\alpha)$ model}

The present model relies on the correlation between the specific moisture capacity, $\alpha$ (i.e. slope of the SWCC) and the one dimensional swell strain and pressure obtained from the loading-after-wetting test (Method C ASTM D4546 - 08) performed only on 95\%MDD compacted specimens of expansive clay.

Physico-mechanical attributes of the soil swelling behaviour are characterized by the cumulative variation of void ratio, matric suction and moisture content undergone during the swell process. Also, hydro mechanical behaviour of swelling soil during the heaving process may be detailed through the hysteretic paths of the drying and wetting SWCCs.

Figure 4 depicts the assumed idealized plot linking the void ratio to the matric suction which allows for the determination of the herein called modified specific moisture content, $\alpha$. The idealized and actual paths exhibited by a soil specimen during hydration are shown in the Figure 4. In all the tested soils, the moisture content and matric suction relationships from the SWCCs are correlated to the corresponding void ratios and moisture contents, thus, void ratio - log matric suction or void ratio - matric suction in $\mathrm{pF}$ plots are acquired. During the swelling process, soil specimen undergoes a decrement in its matric suction and a corresponding void ratio increment. In the herein proposed model, this soil matric suction - void ratio variation is assumed to follow a linear trend (i.e. modified specific moisture capacity).

The slope of the soil matric suction (X-axis) and void ratio (Y-axis) plots (i.e. modified $\alpha$ ) is therefore considered as a significant parameter in representing the variation of void ratio of the soil specimen with soil matric suction during swelling process.

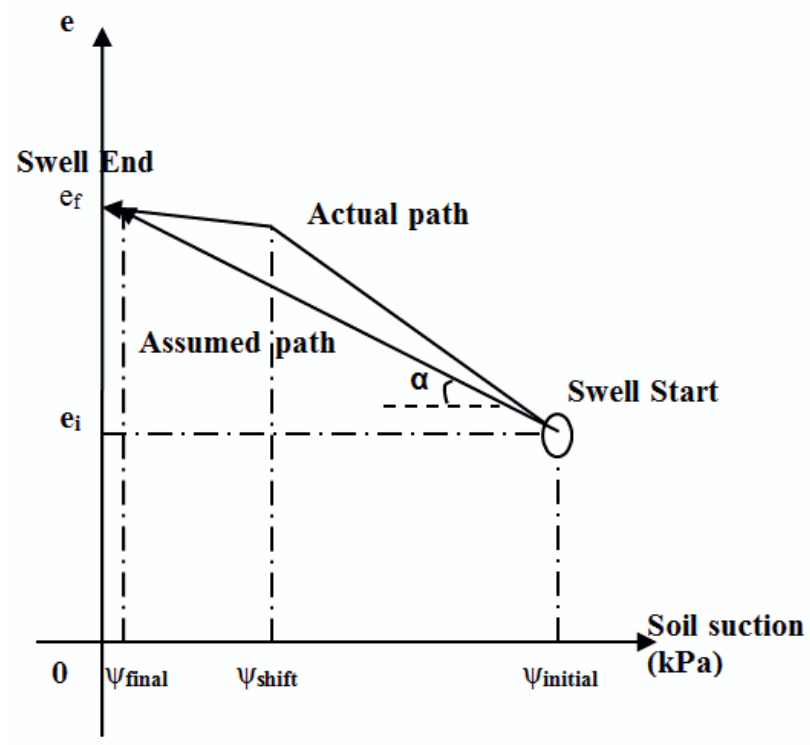

Figure 4. Schematic for the measurement of slope of void ratio and logarithmic of matric suction.

In Figure 4, the $\mathrm{e}_{\mathrm{i}}$ is the initial void ratio (i.e. e when free swell starts), $e_{f}$ is the void ratio when the soil specimen is fully saturated (i.e. e when free swell ends), $\psi_{\text {initial }}$ is the initial matric suction in the soil specimen before swell testing (i.e. existing suction in the sample after compaction at $95 \%$ MDD and optimum moisture content), $\psi_{\text {shift }}$ is the matric suction when a shift on the wetting SWCC is noticed (i.e. small changes in saturation condition take place), $\psi_{\text {final }}$ is the final matric suction at almost full saturation condition and $\alpha$ is the slope of idealized suction - void ratio path. Initially the soil specimen has high matric suction $\left(\psi_{\text {initial }}\right)$ and a lower value of void ratio $\left(\mathrm{e}_{\mathrm{i}}\right)$.

The difference between $\psi_{\text {initial }}$ and $\psi_{\text {final }}$ values generates a negative slope value of the modified $\alpha$, however it is neglected since the actual 'MechanicalHydro' coupling effect is based only on the magnitude of the modified $\alpha$. Swelling process induces an increment in moisture content and void ratio in the soil specimen. As the degree of saturation increases, the void ratio of the soil specimen will increase consequently following a matric suction reduction. This behaviour is clearly noticed in the e-w-log $\psi$ and $\mathrm{e}-\mathrm{w}-\psi$ plots of the five expansive soils. The mentioned plots for one of the soils will be shown in the following sections. 
The slope of the idealized matric suction-void ratio path (i.e. modified specific moisture capacity) is obtained from the wetting SWCC of each soil and is given by the following Equation 1.

$$
\alpha=\frac{e_{\text {final }}-e_{\text {initial }}}{\log \frac{\psi_{\text {final }}}{\psi_{\text {initial }}}}
$$

The swell behaviour exhibited by Burleson soil specimen on an e-w-log $\psi$ and $\mathrm{e}-\mathrm{w}-\psi$ plots is presented in Figure 5 and Figure 6, respectively.

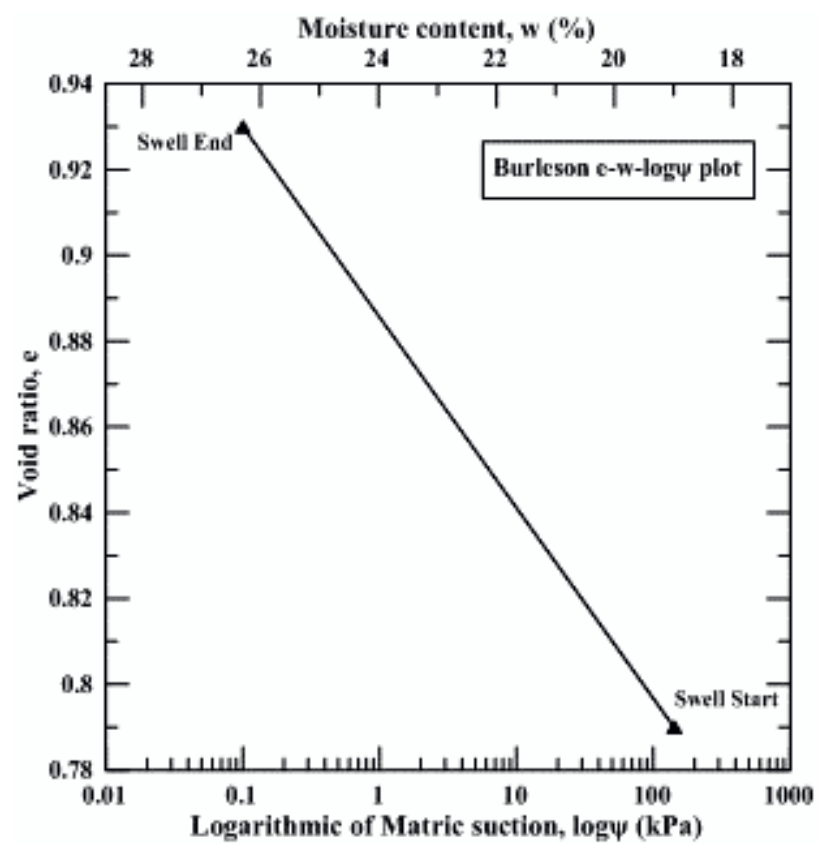

Figure 5. Behaviour of Burleson soil specimen at 95\% MDD on e-w-log $\psi$ plot.

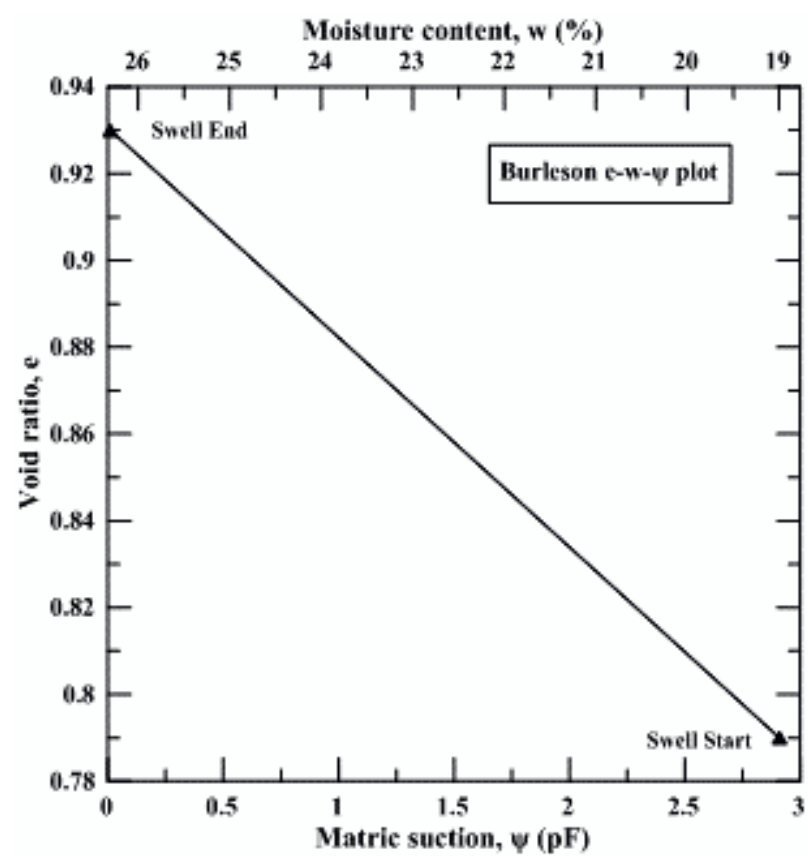

Figure 6. Behaviour of Burleson soil specimen at 95\% MDD on e-w- $\psi$ plot.
The slope of logarithm of matric suction-void ratio and matric suction in $\mathrm{pF}$-void ratio plots (i.e. modified specific moisture capacity, $\alpha$ ) is presented in Table 4.

Table 4. Modified specific moisture capacity, $\alpha$, for all the expansive clays.

\begin{tabular}{ccc}
\hline Soil & $\begin{array}{c}\alpha \text { from } \\
\text { e-w-log } \psi \text { plot }\end{array}$ & $\begin{array}{c}\alpha \text { from } \\
\text { e-w- } \psi \text { plot }\end{array}$ \\
\hline Burleson & 0.0444 & 0.0481 \\
\hline Colorado & 0.0606 & 0.0593 \\
\hline Grapevine 2 & 0.0264 & 0.0259 \\
\hline Mansfield & 0.0690 & 0.0693 \\
\hline Plano & 0.0529 & 0.0528 \\
\hline
\end{tabular}

The relationship established between the measured one dimensional swell strain and pressure and the modified specific moisture capacity, $\alpha$, as obtained from the logarithm of matric suction-void ratio plot and the matric suction in $\mathrm{pF}$-void ratio plot (Table 4), is presented in the following Figure 7 and Figure 8.

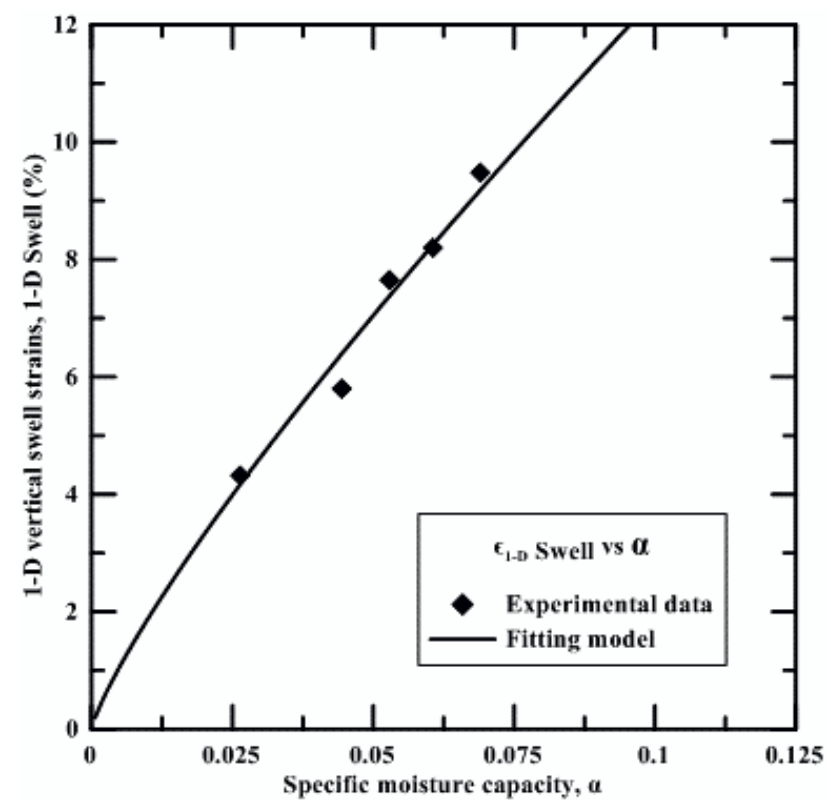

Figure 7. 1 D Swell Strain vs $\alpha$ at 95\% MDD condition on e-w$\log \psi$ plot. 


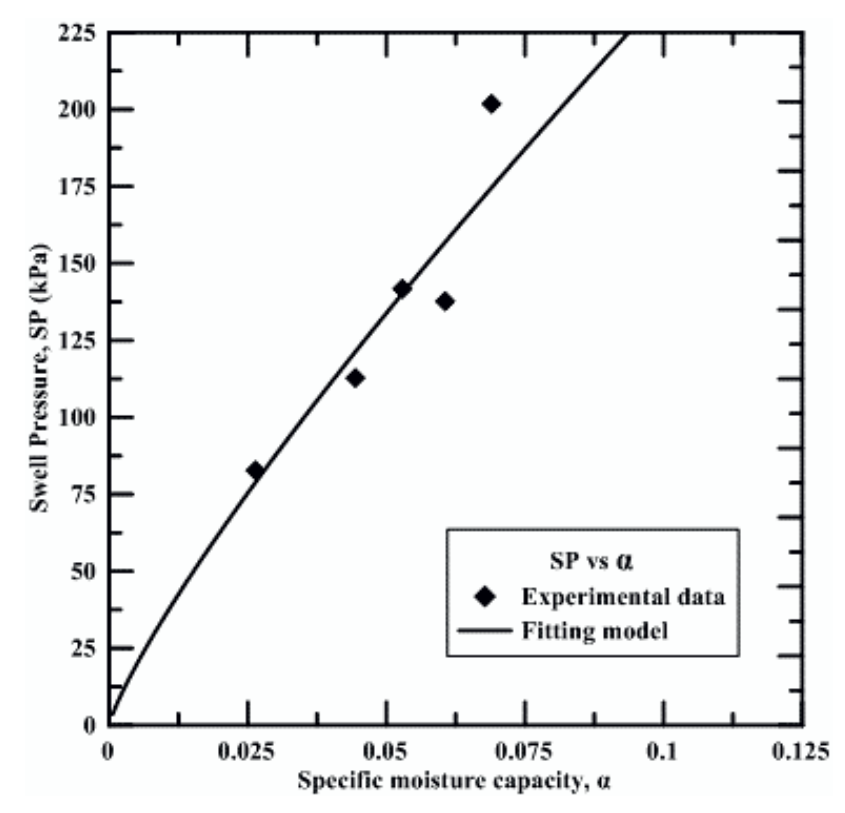

Figure 8. 1 D Swell Pressure vs $\alpha$ at 95\% MDD condition on ew-log $\psi$ plot.

It is possible to notice only a slight variation on the values of the modified specific moisture capacity, $\alpha$, found through the two studied approaches (Table 4), thus, the exponential fitting curves yielded close formulae as presented in Equation 2 pertaining to the one dimensional swell strains and Equation 3 for swell pressure.

$$
\begin{aligned}
& \epsilon_{1-D \text { Swell }}(\%)=82.56 \times \alpha^{0.821} \\
& S P(k P a)=1596.48 \times \alpha^{0.828}
\end{aligned}
$$

The model for 1-D swell strains and pressures showed a good fit with the measured experimental data. The coefficients of determination $\left(\mathrm{R}^{2}\right)$ for these models were found to be 0.97 and 0.92 in the swell strain case and 0.89 and 0.87 , in the swell pressure case. Overall, a direct relationship between the swell strains and swell pressure is observed with modified specific moisture capacity, $\alpha$. Further investigations on diverse test soils are required to refine these formulations derived.

\section{Summary}

A parameter designated herein as the modified specific moisture capacity, $\alpha$, which represents the slope of an idealized path on the soil water characteristic curve (SWCC). This parameter couples the combined effects of the hydro-mechanical related properties of an expansive soil has been used in this research for swell strain and pressure prediction assessments on specimens of clay specimens compacted at $95 \%$ MDD. The samples were tested for one dimensional swell strain and swell pressure using a conventional consolidometer setup following ASTM D-4546 method C. A model correlating one dimensional swell strains and pressures to the specific moisture capacity was derived. The model was established using two equivalent approaches for finding the specific moisture capacity of soils, corresponding to the slope of the logarithm of the matric suction-void ratio plot and the slope of the matric suction in $\mathrm{pF}$-void ratio plot. The proposed model for the prediction of one dimensional swell strains and swell pressures provided reliable results with both of the equivalent approaches, though, the logarithm of the matric suction-void ratio approach yields a higher coefficient of correlation. Similar variation of the proposed model results obtained for soil specimens compacted at 95\% MDD are expected and assumed to occur for specimens compacted at MDD condition.

\section{References}

1. A.J. Puppala, B. Katha, L.R. Hoyos, Geot. Tes. J. ASTM, 27, 6 (2004)

2. Y.M. Mowafy, Trans. Res. Rec., 1032, 23-33 (1985)

3. R.G. McKeen, Proc. $7^{\text {th }}$ Int. Conf. on Exp. Soils, 1, 1-6 (1992)

4. E. Yusuf, O. Erol, Eng. Geol., 92,133-145 (2007)

5. D.G. Fredlund, Proc. 2nd Intern. Conf. on Exp. Clay Soils, 1,435-456 (1969)

6. D.G. Fredlund, J. of Geot. And Geoenv. Eng., 132(3), 286-321 (2006)

7. F. Bernier, Volckaert, G., Alonso, E., and Villar, M. Engineering Geology, vol. 47, pp. 325-338. (1997)

8. P. Delage, Howat, M.D., Cui, Y.J. Engineering Geology, vol. 50, pp. 31-48. (1998)

9. A. Pedarla, Puppala A.J., Hoyos, L.R., Zapata, C.E. and Chittoori B. Unsaturated soils: research and applications, UNSAT 2014, Australia, V 2, pp 951 957 (2014) 